\title{
PERCEPÇÃO DE USUÁRIAS ACERCA DO EXAME DE DETECÇÃO PRECOCE DO CÂNCER DE COLO UTERINO
}

\author{
Karla Torres de Queiroz Neves ${ }^{1}$, Antonio Wendel Nogueira Oliveira ${ }^{1}$, Thatylla Rayssa Alves Ferreira Galvão ${ }^{1}$, \\ Ilziane Tomaz Ferreira ${ }^{1}$, Elisa Matias Mangane ${ }^{1}$, Leilane Barbosa de Sousa ${ }^{2}$
}

RESUMO: Objetivou-se descrever a percepção de usuárias acerca do exame de detecção precoce do câncer de colo uterino. Trata-se de pesquisa descritiva desenvolvida em cinco Unidades Básicas de Saúde de um município do interior do estado do Ceará, de janeiro a abril de 2015. Foram entrevistadas 15 usuárias que realizaram exame ginecológico. Os resultados foram submetidos à análise de conteúdo e classificados em categorias: significado do exame, frequência de realização, sentimentos vivenciados e motivos para recusa. As entrevistadas conhecem o objetivo do exame e o realizam periodicamente. A realização por profissional de saúde do sexo masculino pode constituir motivo de recusa do exame. A adesão é influenciada pela relação de confiança com o profissional. Conclui-se que as entrevistadas percebem o exame como importante e que eventuais motivos para a recusa podem ser evitados por meio do fortalecimento de vínculos no serviço.

DESCRITORES: Qualidade da assistência à saúde; Saúde da mulher;Saúde sexual e reprodutiva; Teste de papanicolaou; Neoplasias do colo do útero.

\section{USERS' PERCEPTION OF SCREENING TESTS FOR PREVENTING CERVICAL CANCER}

\begin{abstract}
The present study aimed to describe the perception of users of the test for early detection of cervical cancer. Descriptive study conducted in five Basic Health Units in a city in the inland of the state of Ceará, from January to April 2015. Fifteen women who underwent routine screening tests for early detection of cervical cancer were interviewed. The data produced underwent content analysis and was classified into the following categories: user's perception of the test, frequency of screenings, feelings experienced by the respondents and reasons for refusing cervical screening. The participants are aware of the purpose of the test and periodically undergo the screening. One reason for some women refusing cervical screening is that they do not want it performed by male doctors. Adherence is influenced by a relationship of trust with health professionals. It was concluded that the respondents perceive the test as important and that any possible reasons for refusing cervical screening can be avoided by improving provider-patient relationship in health care.
\end{abstract}

DESCRIPTORS: Quality of health care; Women's health; Sexual and reproductive health; Pap smear test; Cervical neoplasias.

\section{PERCEPCIÓN DE USUARIAS ACERCA DEL EXAME DE DETECCIÓN PRECOZ DEL CÁNCER DE CUELLO DE ÚTERO}

RESUMEN: Fue objetivo del estudio describir la percepción de usuarias acerca de la prueba de detección precoz del cáncer de cuello uterino. Es una investigación descriptiva desarrollada en cinco Unidades Básicas de Salud de un municipio de interior del estado de Ceará, de enero a abril de 2015. Quince usuarias que realizaron prueba ginecológica fueron entrevistadas. Los resultados fueron sometidos al análisis de contenido y clasificados en categorías: significado de la prueba, frecuencia de realización, sentimientos causados y motivos para recusación. Las entrevistadas conocen el objetivo de la prueba y la hacen periodicamente. La realización por profesional de salud del sexo masculino puede constituir motivo de recusación de la prueba. La adhesión es influenciada por la relación de confianza con el profesional. Se concluye que las entrevistadas perciben la prueba como importante y que eventuales motivos para recusación pueden ser evitados por medio del fortalecimiento de vínculos en el servicio.

DESCRIPTORES: Calidad da asistencia a la salud; Salud de la mujer; Salud sexual y reproductiva; Prueba de papanicolau; Neoplasias del cuello del útero.

${ }^{1}$ Discente de Enfermagem.Universidade da Integração Internacional da Lusofonia Afro-Brasileira. Acarape, CE, Brasil. ${ }^{2}$ Enfermeira. Doutora em Enfermagem. Docente da Universidade da Integração Internacional da Lusofonia Afro-Brasileira. Fortaleza, CE, Brasil.

Autor Correspondente:

Karla Torres de Queiroz Neves

Universidade da Integração Internacional da Lusofonia Afro-Brasileira

R. Henrique Bessa, 82 - 6785000 - Acarape, CE, Brasil

Email: thekarlatorres@gmail.com
Recebido: $17 / 03 / 2016$ Finalizado: 07/10/2016 


\section{INTRODUÇÃO}

A realização do exame de detecção precoce do câncer de colo uterino é de fundamental importância, pois essa neoplasia é apontada como a segunda mais importante causa de morte por câncer em mulheres no Brasil. Para 2016, estimou-se cerca de 16.340 novos casos, com o risco estimado de 15,85 casos para cada 100 mil mulheres, sendo superado somente pelo câncer de mama, o que caracteriza a situação como problema de saúde pública ${ }^{(1)}$.

O Ministério da Saúde do Brasil preconiza que toda mulher com vida sexual ativa realize o exame de detecção precoce do câncer de colo uterino, sendo priorizado para mulheres com idade entre 25 e 60 anos. Inicialmente, o exame deve ser realizado anualmente e, após dois exames anuais consecutivos negativos, a periodicidade poderá ser trienal ${ }^{(2)}$.

O exame de detecção precoce do câncer de colo uterino é realizado de modo cotidiano há décadas, mas ainda assim induz comportamentos e sentimentos diversificados entre as mulheres. O procedimento, muitas vezes, é considerado pela mulher como invasivo, pois expõe seu corpo equestões relacionadas à sexualidade. O caráter do exame pode gerar sentimentos negativos,que vão desde o desconforto físico ao constrangimento de expor o seu corpo para outra pessoa ${ }^{(3)}$.

Para vencer as barreiras e melhorar a adesão da mulher ao exame de detecção precoce do câncer de colo uterino,é preciso dar maior atenção aos relatos e experiências de quem já se submeteu a ele. Então, compreender como as mulheres veem o exame, o que pensam sobre ele e os sentimentos por elas vivenciados durante a realização do mesmo é via para planejar e nortear os serviços de saúde ${ }^{(4)}$.

O objetivo do presente estudo foi descrever a percepção de usuárias acerca do exame de detecção precoce do câncer de colo uterino.Os resultados desta pesquisa poderão contribuir com o fornecimento de informações que poderão embasar estratégias de orientação e fortalecimento do vínculo entre paciente e serviço de saúde, buscando aumentar a adesão ao exame retrocitado.

\section{MÉTODO}

Trata-se de pesquisa descritiva de caráter qualitativo, desenvolvida nas Unidades Básicas de Saúde (UBS) de um município do interior do Estado do Ceará. O município conta com 11 UBS. Entre estas, 06 foram excluídas, pois 04 localizavam-se em região serrana e de localização geográfica de difícil acesso, 01 localizava-se em área de alta periculosidade e em outra a equipe se recusou a participar do estudo. O campo de pesquisa, portanto, foi composto por 05 UBS.

A pesquisa foi desenvolvida de agosto de 2014 a julho de 2015. A coleta de dados nas UBS ocorreu durante os meses de janeiro a abril de 2015, nos dias de práticas de detecção precoce do câncer de colo uterino. Em cada uma das UBS a consulta ginecológica, na qual é realizado o exame detecção precoce do câncer de colo uterino, é ofertada em um turno por semana, com agendamento de aproximadamente oito pacientes por semana.

A população foi composta por todas as usuárias que foram atendidas durante a avaliação técnica do profissional que executou o exame de detecção precoce do câncer de colo de útero. Foram incluídas as mulheres que possuíam idade igual ou superior a 18 anos e que já haviam realizado pelo menos um exame de detecção precoce do câncer de colo uterino antes do dia da coleta de dados. Foram excluídas do estudo as usuárias que possuíam alguma dificuldade cognitiva. Com base nestes critérios, foram selecionadas 15 mulheres.

O primeiro contato com as usuárias aconteceu no local do estudo, quando foi feito o convite para participar da pesquisa e explicados os objetivos, os procedimentos, os benefícios do estudo e realizada a leitura do Termo de Consentimento Livre e Esclarecido (TCLE). As atividades foram ocorreram logo após a aceitação do convite e assinatura do TCLE pelas participantes.

A coleta de dados foi desenvolvida por meio de entrevista semiestruturada, realizada de forma individual. A obtenção e o registro dos resultados foram feitos pelos pesquisadores, com o auxílio de um gravador de som e do diário de campo. 
As entrevistas só foram encerradas assim que as informações obtidas se tornaram saturadas, a fim de que a inclusão de novas participantes não resultasse em redundância ou repetição. A amostragem por saturação é útil quando se deseja a obtenção de dados qualitativos, uma vez que o que se busca é o significado e a qualidade de informações subjetivas, não a quantidade ${ }^{(5)}$. Dessa forma, para cada UBS avaliada foram entrevistadas, no mínimo, três usuárias.

Os achados foram submetidos à técnica de codificação dos conteúdos das falas, composta pelas fases de pré-análise, exploração do material (ou codificação), tratamento dos resultados, inferência e interpretação ${ }^{(6)}$. Os resultados foram apresentados nas seguintes categorias, que emergiram dos depoimentos das entrevistadas: significado do exame, frequência de realização, sentimentos vivenciados e motivos para recusa.

Todas as etapas do estudo estão em conformidade com as instruções presentes na Resolução $\mathrm{n}^{\circ}$ 466/2012, do Conselho Nacional de Saúde, referente a estudos a serem realizados com seres humanos ${ }^{(7)}$. Esta pesquisa teve o compromisso de tratar as participantes com dignidade, respeitá-las em sua autonomia e defendê-las em sua vulnerabilidade, tendo como princípios resguardar a integridade dos valores, dos modos de vida e do ambiente cultural das pessoas envolvidas na pesquisa, bem como primar pela privacidade, ressaltar a relação risco/benefício (de forma a procurar fornecer o máximo de benefícios e o mínimo de danos e riscos), não discriminar as participantes e proteger grupos vulneráveis.

Esta pesquisa foi autorizada pela Secretaria Municipal de Saúde do Município e aprovada pelo Comitê de Ética em Pesquisa da Universidade da Integração Internacional da Lusofonia Afro-Brasileira (UNILAB), sob parecer número 1.269.145. Nos resultados foi garantido o anonimato das participantes, que foram denominadas pela letra $\mathrm{P}$ (participante) acompanhada por um número cardinal e seguida pela letra $U$ (unidade de saúde) acompanhado também por um número cardinal.

\section{RESULTADOS}

Os resultados obtidos foram organizados e agrupados em quatro categorias pré-estabelecidas. A primeira categoria diz respeito ao significado que o exame preventivo tem para a usuária, a segunda apresenta a frequência com a qual essas mulheres realizam o exame, a terceira está relacionada aos sentimentos vivenciados durante a realização do mesmo e a quarta aborda os possíveis motivos que poderiam levar a mulher a se recusar a fazer o exame.

As entrevistadas tinham idade de 22 a 69 anos. Das 15 participantes, 11 eram casadas e quatro solteiras. Em relação ao nível de escolaridade, seis tinham apenas o ensino fundamental, outras seis o ensino médio completo e três eram analfabetas.

\section{Significado do exame}

Para o controle do câncer de colo uterino é essencial que as mulheres conheçam o significado da consulta ginecológica e sua importância. Todas as entrevistadas sabiam que o intuito do exame de detecção precoce do câncer de colo de útero é identificar alterações que possam progredir para o câncer. Sobre o significado da prática, as expressões foram as seguintes:

Significa saúde, por que só assim descobre se tem alguma doença. Muita mulher só procura [o serviço de saúde] quando sente alguma coisa. Aí já está sem jeito. (P1U3)

É importante fazer a prevenção do câncer todo ano, você está se prevenindo e é uma obrigação das mulheres fazer a prevenção. Faço todo ano e o câncer está atacando muita gente, muitas mulheres de todas as idades. (P1U4)

A importância do exame é relacionada à possibilidade de descoberta de algum agravo que possa favorecer o desenvolvimento do câncer, conforme se verifica nas falas:

É importante, porque descobre algumas doenças que a gente tem. Hoje vim para realizar a prevenção porque tinha feito um tratamento com ela[enfermeira].(P1U2) 
É para saber se tem ou não[doença] para que, caso tenha, venha-se detectar ainda cedo para iniciar com o tratamento. (P3U2)

[...] a prevenção de câncer de colo de útero é bom saber como está por dentro. (P2U3)

\section{Frequência de realização}

Das 15 entrevistadas, 10 referiram realizar o exame anualmente. As que não realizam com esta frequência atribuíram o ocorrido à mudança de enfermeira da Unidade Básica de Saúde (UBS), à dificuldade no agendamento de consultas e outras situações.

Antes fazia todo ano e, por descuido, não fiz mais e me arrependi [...] então fui me descuidando e deixando passar. (P3U1)

A última vez que fiz foi em 2008, porque na minha localidade foi mudada a enfermeira e eu queria me consultar apenas com ela[...] Ela atende a gente muito bem e respeita. (P2U2)

Há quatro anos que não fazia por dificuldade de marcação. Antes realizava todo ano. (P3U3)

\section{Sentimentos vivenciados}

O exame de prevenção do câncer de colo de útero constitui, ao mesmo tempo, oportunidade para cuidar de sua saúde e situação que pode envolver sentimentos de constrangimento.

Acerca dos sentimentos vivenciados em virtude do exame, observou-se que 10 entrevistadas referiram sentirem-se tranquilas e cinco relataram algum tipo de constrangimento. As pacientes que se sentiram tranquilas explicaram que a enfermeira contribuiu para isto, proporcionando um ambiente de assistência acolhedor.

Me sinto nervosa, não gosto, apesar de a enfermeira deixar bastante à vontade; é algo que me constrange, sinto um incômodo. (P2U3)

Acho incômodo, mas a enfermeira me deixa à vontade [...].(P3U3)

A doutora[enfermeira] faz a gente se sentir calma[...] Só faço com ela, onde ela estiver vou atrás dela. (P2U2)

[...] faço há muitos anos com a mesma enfermeira e ela me trata bem. Há 10 anos que eu faço com a mesma enfermeira.(P1U4)

\section{Motivos para recusa}

Das 15 entrevistadas, 12 relataram não existir motivos para que recusem fazer o exame, alegando que o mais importante para elas é cuidar da saúde. Duas pacientes relataram que a enfermeira contribuiu para que elas se sentissem à vontade. Outras duas pacientes falaram sobre a questão de ser atendida por um profissional do sexo oposto, sendo que uma relatou que se recusaria a fazer o exame e a outra ficaria com receio; porém, esta afirmou que não deixaria de realizá-lo.

Recusaria realizar o exame de prevenção caso fosse atendida por um médico, pois não me sentiria bem, à vontade, sendo tocada por um outro homem que não fosse meu namorado. (P3U2)

Se mudar para médico, se tivesse que fazer com médico, ficaria com receio, mas não deixaria de fazer. (P1U4)

\section{DISCUSSÃO}


O câncer de colo de útero é o terceiro tipo de câncer mais comum entre as mulheres. Anualmente são diagnosticados cerca de 530 mil novos casos no mundo; dos quais mais da metade culmina em óbito. Esse tipo de câncer é caracterizado pelo crescimento desordenado do epitélio que reveste o órgão, o que compromete o tecido subjacente (estroma), podendo invadir órgãos e estruturas adjacentes ou à distância( ${ }^{(2)}$.

Pelos discursos das depoentes, nota-se que a informação sobre o câncer de colo uterino representa relevante critério que contribui para a adesão ao exame. Quando o exame é realizado sem explicação de seu significado e de sua importância, ele pode gerar sentimentos negativos, o que dificulta a criação de um espaço de autoconhecimento do corpo e da sexualidade da mulher ${ }^{(8)}$. Isso pode interferir negativamente na procura e adesão ao exame, comprometendo o diagnóstico precoce.

As usuárias reconhecem a importância do exame preventivo para a preservação da saúde, fato que colabora para facilitar a adesão à prática da prevenção. Embora se admita que ter o conhecimento da importância do exame não obrigatoriamente implique na sua realização, conhecer os benefícios do mesmo consiste em um fator positivo para a adesão(9). Essa adesão com base no conhecimento parece resultar, sobretudo, de reflexões sobre a necessidade de realização da consulta ginecológica para identificação de lesões assintomáticas e que podem ser agravadas com o diagnóstico tardio.

As entrevistadas referiram realizar o exame com o intuito de descobrir doenças de forma precoce e que, assim, sentem-se mais aliviadas e seguras no que diz respeito à sua saúde. As falas também sugerem que as mulheres conhecem alguns conceitos básicos sobre o exame e sua importância. Os serviços de saúde prestados à comunidade e aos profissionais, principalmente enfermeiros, devem orientar sobre o que é e qual a importância e os benefícios do exame de detecção precoce do câncer de colo uterino, pois a realização periódica do mesmo possibilita redução da mortalidade ${ }^{(10)}$.

Além do conhecimento sobre a importância do exame, as mulheres devem atentar também para a frequência de realização do mesmo. No que diz respeito a isso, o Ministério da Saúde do Brasil recomenda que toda mulher com vida sexual ativa realize o exame uma vez ao ano(2).

As entrevistadas percebem a realização periódica do exame de detecção precoce do câncer de colo uterino como essencial para o acompanhamento da evolução de alterações e tratamento em tempo hábil para obtenção da cura. A maneira mais eficiente para controlar esse tipo de tumor é quando essas lesões são diagnosticadas e tratadas em seus estágios iniciais, o que torna possível a cura de quase $100 \%$ dos $\operatorname{casos}^{(10)}$.

Além de conhecerem os benefícios do exame de detecção precoce do câncer de colo e de sua realização periódica, a percepção das mulheres sobre o mesmo perpassa pelo âmbito da subjetividade, mais especificamente pelos sentimentos vivenciados a respeito desse exame. Ainda que, na maioria das vezes, o exame implique em sentimentos negativos, algumas mulheres se referem a ele com uma visão mais otimista e positiva, afirmando tranquilidade durante a realização do mesmo, isso em virtude do acolhimento dos enfermeiros durante o exame. Os profissionais devem colaborar para que o momento seja tranquilo, no qual as mulheres tenham a oportunidade de serem ouvidas e sintam-se protegidas e respeitadas $^{(3)}$.

A relação profissional-paciente faz-se necessária para o desenvolvimento de um clima de empatia,no qual o profissional atue não somente com o preparo técnico, mas também com sensibilidade e intuição, visando estabelecer um vínculo de confiança. O estabelecimento deste vínculo facilita o diálogo com as usuárias do serviço, possibilitando a abordagem de questões relacionadas ao conhecimento do próprio corpo, de sua anatomia, de seu funcionamento e de suas representações psicológicas, colaborando para a quebra de tabus que cercam o corpo feminino ${ }^{(11)}$.

Além de o estabelecimento do vínculo entre o profissional e o cliente facilitar a adesão ao exame preventivo, ele ainda colabora com o processo de educação em saúde, que é considerado uma maneira de valorizar os profissionais e promover transformações da realidade social ${ }^{(12)}$. Cabe aos profissionais de saúde, principalmente aos da Enfermagem, devido à sua proximidade com a comunidade, elaborar ações e estratégias que sejam capazes de desvendar os receios sobre o exame citopatológico. Essas ações contribuem para o aumento da demanda de usuárias atendidas no serviço e para o controle do câncer de colo uterino ${ }^{(13)}$. 
Apesar do conhecimento adquirido com sobre o exame, a atitude que as mulheres têm sobre o próprio corpo não está livre de influências sociais, culturais e econômicas. Mesmo que sejam conceituadas como profissionais bem-sucedidas, competindo no mercado de trabalho por cargos com os homens, as mulheres ainda exercem outros papéis na sociedade, como o de mãe e o de esposa. Esses papéis parecem estar diretamente relacionados ao cuidado do próprio corpo, uma vez que, envolta com tantas atividades, a mulher tende a negligenciar o cuidado da própria saúde. Este cuidado, ao invés de se originar a partir de uma atitude positiva de busca de bem-estar e qualidade de vida, surge, muitas vezes, como resultado de um sinal ou sintoma de alerta que ocasiona medo da doença, da morte e da dor ${ }^{(3)}$.

No que se refere a possíveis motivos de recusa em relação à realização do exame ginecológico, estudos relatam que alguns fatores como falta de conhecimento sobre a importância do exame, a vergonha, o medo em relação ao câncer e ao próprio exame, inatividade sexual, embaraço, dor, nível socioeconômico e questões cultural podem ameaçar a adesão ao exame, pois o mesmo é visto por muitas mulheres como um exame que invade a privacidade e a integralidade corporal da mulher ${ }^{(7,14)}$.

A exposição do corpo, principalmente a um profissional de saúde do sexo oposto, constitui fator de constrangimento pelas entrevistadas; contudo, a consciência sobre a importância do exame e o vínculo de confiança estabelecido entre profissional de saúde e usuária minimizam sentimentos negativos provenientes dessa exposição. O modo como algumas mulheres reagem ao expor seu corpo, vê-lo sendo manipulado e examinado por um profissional da saúde, revela o quanto a sexualidade influencia a vida da mulher; afinal, trata-se de tocar, manusear e expor órgãos e zonas erógenas. Assim, surge a questão de as mulheres associarem sempre a exposição das genitálias à sexualidade, o que produz sentimento de vergonha em relação aos seus órgãos sexuais ${ }^{(10)}$.

\section{- CONSIDERAÇÕES FINAIS}

O estudo revelou que a percepção das mulheres acerca do exame de detecção precoce do câncer de colo uterino é de fundamental importância para a adesão ao mesmo. Compreender o olhar e os sentimentos das mulheres que se submetem à consulta ginecológica é guia para o planejamento e direcionamento de ações visando aumentar a adesão ao exame preventivo.

Evidenciou-se que as mulheres entrevistadas conhecem o intuito do exame e o realizam com a periodicidade recomendada pelo Ministério da Saúde do Brasil. Além disso, as mulheres mostraram que submeter-se ao exame consiste em forma de autocuidado e prevenção de doenças, o que contribui para a promoção de sentimentos positivos durante a realização do mesmo.

A relação profissional-paciente revelou-se crucial para que as usuárias se sentissem à vontade durante a consulta ginecológica,o que enfatiza a importância do estabelecimento de vínculo de confiança entre a usuária e o profissional de saúde, pois esse fator pode facilitar a adesão ao exame e contribui para que o procedimento seja percebido com tranquilidade.

Neste estudo, a maioria das mulheres relatou não haver motivos para recusa do exame, alegando que o mais importante é cuidar da saúde, o que evidencia o conhecimento, mesmo que limitado, acerca dos benefícios da prevenção. Poucas usuárias relataram algum tipo de constrangimento associado ao exame; sendo que este sentimento, quando mencionado, estava relacionado à hipótese de ser atendida por um profissional do sexo oposto.

A presente pesquisa foi limitada a apenas um município do interior do estado do Ceará; assim, sugere-se que estudos semelhantes sejam realizados em outras cidades, especialmente capitais, para verificar se os achados estão relacionados a questões culturais de cidades do interior ou estão presentes também em grandes centros.

\section{- REFERÊNCIAS}

1. Brasil. Instituto Nacional de Câncer José Alencar Gomes da Silva (INCA). Coordenação de Prevenção e Vigilância Estimativa 2016: Incidência de câncer no Brasil. [Internet] Rio de Janeiro: INCA; 2015 [acesso em 04 
mar 2016]. Disponível: http://www.inca.gov.br/estimativa/2016/.

2. Ministério da Saúde (BR). Secretaria de Atenção à Saúde. Departamento de Atenção Básica. Controle dos cânceres do colo do útero e da mama. [Internet] Brasília: Ministério da Saúde; 2013 [acesso em 06 mar 2016 ]. Disponível: http://bvsms.saude.gov.br/bvs/publicacoes/controle_canceres_colo_utero_2013.pdf.

3. Matão MEL, de Miranda DB, Campos PHF, Machado AF, Ornelas ER. Percepção de mulheres acerca do exame colpocitológico. R. Enferm. Cent. O. Min. [Internet] 2011;1(1) [acesso em 04 mar 2016] Disponível: http://dx.doi. org/10.19175/recom.v0i0.24.

4. Garcia CL, Pereira HC, Marinho MNASB. Percepção das mulheres acerca do exame de prevenção do câncer cervico-uterino. RBPS. [Internet] 2010;23(2) [acesso em 29 fev 2016]. Disponível: http://dx.doi. org/10.5020/18061230.2010.P118.

5. Fontanella BJB, Ricas J, Turato ER. Amostragem por saturação em pesquisas qualitativas em saúde: contribuições teóricas. Cad. Saúde Pública. [Internet] 2008;24(1) [acesso em 06 mar 2016]. Disponível:http://dx.doi.org/10.1590/ S0102-311X2008000100003.

6. Bardin L. Análise de conteúdo. São Paulo: Edições 70; 2011.

7. Ministério da Saúde (BR). Conselho Nacional de Saúde. Diretrizes e Normas regulamentadoras de pesquisa envolvendo seres humanos. Resolução n. 466, de 12 de dezembro de 2012. Brasília; 2012.

8. Jorge RJB, Diógenes MAR, Mendonça FAC, Sampaio LRL, Jorge Júnior R. Exame Papanicolaou: sentimentos relatados por profissionais de enfermagem ao se submeterem a esse exame. Ciênc. saúde coletiva.[Internet] 2011;16(5)[acesso em 11 mar 2016] Disponível: http://dx.doi.org/10.1590/S1413-81232011000500013.

9. Nascimento LC, Nery IS, Silva AO. Conhecimento cotidiano de mulheres sobre a prevenção do câncer de colo de útero. Rev. enferm. UERJ. [Internet] 2012;20(4) [acesso em 10 mar 2016] Disponível: http://www.e-publicacoes. uerj.br/index.php/enfermagemuerj/article/view/4813.

10. Ormonde Junior JC, de Oliveira LD, de Sá RM. Fatores de adesão e não adesão das mulheres ao exame colpacitológico.Rev. Gest. Saúde. [Internet] 2015;6(1) [acesso em 08 mar 2016] Disponível: http://gestaoesaude. unb.br/index.php/gestaoesaude/article/view/946.

11. Peretto M, Drehmer LBR, Bello HMR. O não comparecimento ao exame preventivo do câncer de colo uterino: razões declaradas e sentimentos envolvidos. Cogitare Enferm. [Internet] 2012;17(1) [acesso em 07 mar 2016] Disponível: http://dx.doi.org/10.5380/ce.v17i1.26371.

12. Lima AS, Nicolato FV, Dutra HS, Bahia MTR, Farah BF. A educação permanente na gestão da atenção primaria de saúde no sistema único de saúde. Rev enferm UFPE on line. [Internet]2015;9(Suppl 4)[acesso em 06 mar 2016] Disponível: http://www.revista.ufpe.br/revistaenfermagem/index.php/revista/article/viewFile/7088/pdf_7945.

13. Santos RFA, Cordeiro CA, Braga LS, de Moraes MN, Araújo VS, Dias MD. Conhecimento de idosas sobre o exame citopatológico. Rev enferm UFPE on line. [Internet] 2015;9(2) [acesso em 01 mar 2016] Disponível: http:// www.revista.ufpe.br/revistaenfermagem/index.php/revista/article/viewFile/5463/pdf_7101.

14. Silva JKS, Silva JS, dos Santos JA, Amorim ASR. Prevenção do câncer de colo uterino: um enfoque a não adesão.Rev Enferm UFPI. [Internet] 2013;2(3) [acesso em 12 mar 2016] Disponível: http://www.ojs.ufpi.br/index. php/reufpi/article/view/1132/0. 